\title{
Communication \\ FY3E GNOS II GNSS Reflectometry: Mission Review and First Results
}

\author{
Guanglin Yang ${ }^{1,2,+}$, Weihua Bai ${ }^{3,4,5,6,7,+}$, Jinsong Wang ${ }^{1,2, *}$, Xiuqing $\mathrm{Hu}^{1}$, Peng Zhang ${ }^{1}$ (D), Yueqiang Sun ${ }^{3,4,5,6,7}$, \\ Na Xu ${ }^{1}$, Xiaochun Zhai ${ }^{1}$, Xianjun Xiao ${ }^{1}$, Junming Xia ${ }^{3,4,6,7}$, Feixiong Huang ${ }^{3,4,6,7}$ (D, Cong Yin ${ }^{3,4,6,7}$, Qifei Du ${ }^{3,4,6,7}$, \\ Xianyi Wang ${ }^{3,4,6,7}$, Yuerong Cai ${ }^{3,4,6,7}$, Xiangguang Meng ${ }^{3,4,6,7}$ D, Guangyuan Tan $3,4,6,7$, Peng Hu ${ }^{3,4,6,7}$ \\ and Congliang $\mathrm{Liu}^{3,4,6,7}$
}

check for
updates

Citation: Yang, G.; Bai, W.; Wang, J.;

Hu, X.; Zhang, P.; Sun, Y.; Xu, N.;

Zhai, X.; Xiao, X.; Xia, J.; et al. FY3E GNOS II GNSS Reflectometry: Mission Review and First Results. Remote Sens. 2022, 14, 988. https:// doi.org/10.3390/rs14040988

Academic Editors: Nereida Rodriguez-Alvarez, Mary Morris and Joan Francesc Munoz-Martin

Received: 12 January 2022

Accepted: 14 February 2022

Published: 17 February 2022

Publisher's Note: MDPI stays neutral with regard to jurisdictional claims in published maps and institutional affiliations.

Copyright: (c) 2022 by the authors. Licensee MDPI, Basel, Switzerland. This article is an open access article distributed under the terms and conditions of the Creative Commons Attribution (CC BY) license (https:// creativecommons.org/licenses/by/ $4.0 /)$.
1 National Satellite Meteorological Center, China Meteorological Administration, Beijing 100081, China; yglyang@cma.gov.cn (G.Y.); huxq@cma.gov.cn (X.H.); zhangp@cma.gov.cn (P.Z.); xuna@cma.gov.cn (N.X.); zhaixc@cma.gov.cn (X.Z.); xiaoxj@cma.gov.cn (X.X.)

2 Key Laboratory of Space Weather, National Center for Space Weather, China Meteorological Administration, Beijing 100081, China

3 National Space Science Center, Chinese Academy of Sciences, Beijing 100190, China; baiweihua@nssc.ac.cn (W.B.); syq@nssc.ac.cn (Y.S.); xiajunming@nssc.ac.cn (J.X.); huangfeixiong@nssc.ac.cn (F.H.); yincong@nssc.ac.cn (C.Y.); dqf@nssc.ac.cn (Q.D.); wxy@nssc.ac.cn (X.W.); cyr@nssc.ac.cn (Y.C.); xgmeng@nssc.ac.cn (X.M.); tanguangyuan@mails.ucas.ac.cn (G.T.); hupeng@nssc.ac.cn (P.H.); lcl@nssc.ac.cn (C.L.)

4 Beijing Key Laboratory of Space Environment Exploration, Chinese Academy of Sciences, Beijing 100190, China

5 School of Astronomy and Space Science, University of Chinese Academy of Sciences, Beijing 100049, China

6 Joint Laboratory on Occultations for Atmosphere and Climate, National Space Science Center, Chinese Academy of Sciences, Beijing 100190, China

7 Key Laboratory of Science and Technology on Space Environment Situational Awareness, Chinese Academy of Sciences, Beijing 100190, China

* Correspondence: wangjs@cma.gov.cn

+ These authors contributed equally to this work.

\begin{abstract}
FengYun-3E (FY3E), launched on 5 July 2021, is one of China's polar-orbiting meteorological satellite series. The GNOS II onboard FY3E is an operational GNSS remote sensor that for the first time combines GNSS radio occultation (GNSS RO) and GNSS reflectometry (GNSS-R). It has eight reflection channels that can track eight specular points at the same time, receiving reflected signals from multiple GNSS systems, including GPS, BeiDou and Galileo. The basic GNSS-R output generated by GNOS II is a $122 \times 20$ non-uniform delay-Doppler map whose high resolution portion captures more information near the specular point. This paper introduces the GNSS-R aspect of the FengYun-3E GNOS II, including the instrument, power calibration and wind speed retrieval algorithm. Preliminary validation results for its first four months of data are also presented. After preliminary quality control, the overall wind speed error is less than $2 \mathrm{~m} / \mathrm{s}$ at wind speeds below $20 \mathrm{~m} / \mathrm{s}$ for data from both GPS satellites and BeiDou satellites when compared to the ECMWF reanalysis winds.
\end{abstract}

Keywords: FY3E; GNOS II; GNSS-R; GNSS RO; ocean wind

\section{Introduction}

Global navigation satellite system reflectometry (GNSS-R), first proposed in 1993 [1], is technology that uses reflected signals from GNSS satellites such as GPS, BeiDou (BDS), GLONASS and Galileo for remote sensing. Geophysical parameters, including ocean surface winds, sea surface height, soil moisture, vegetation biomass, ice properties and snow water equivalent, can be retrieved [2-6]. It has been the focus of recent geophysical research, as it shows special characteristics to complement other passive and active Earth observation methods. One significant uniqueness of GNSS-R is its utilization of existing 
and abundant GNSS satellites from multiple constellations, which provide stable and continuous transmission signals.

After a large number of airborne and land-based experiments, the GNSS-R technique was demonstrated by a series of spaceborne science missions. The first satellite mission was the UK Disaster Monitoring Constellation (UK-DMC) launched in 2003 [7]. It was followed by the UK TechDemoSat-1 launched in 2014 [8]. In 2016, NASA launched the Cyclone Global Navigation Satellite System (CYGNSS), which is a constellation of eight small satellites that can provide ocean surface wind observations with the coverage of latitude \pm 38 degrees for the monitoring of tropical cyclones [9,10]. In 2019, the first Chinese GNSS-R mission, BuFeng-1 A/B twin satellites, was launched, which retrieved ocean wind speeds using reflected signals from both GPS and BeiDou satellites [11]. In 2020, The ESA FSSCat mission was launched, aiming for land and ice applications. It includes two $6 \mathrm{U}$ CubeSats, both of which carry a dual microwave payload combining GNSS-R and an $\mathrm{L}$-band radiometer for interference detection and mitigation [12]. Those science missions provided valuable data for the scientific research, and the potential of spaceborne GNSS-R for the observation of ocean, land and ice has been validated.

The FengYun-3E (FY3E) satellite is the fifth of China's FengYun series of polar-orbiting meteorology satellites, following from predecessors FY3C and FY3D. It is the world's first early morning orbit weather satellite that will fill in the gaps of other polar-orbiting meteorology satellites, which are mostly in morning or afternoon orbits. On July 5, 2021, it was successfully launched at the Jiuquan Satellite Launch Center, China [13]. The Global Navigation Satellite System Occultation Sounder II (GNOS II) onboard the FY3E satellite is the upgraded version of the GNOS used on FY3C and FY3D satellites [14-16]. Besides the GNSS radio occultation (GNSS RO) and precise orbit determination implemented by GNOS, GNOS II can additionally provide GNSS-R measurements. As an integrated GNSS remote sensor, GNOS II can measure the ionosphere, the atmosphere and Earth's surface in three dimensions. One uniqueness of GNOS II is that it can receive GNSS reflected signals from multiple constellations, including GPS, BDS and Galileo. Moreover, GNOS II works together with a scatterometer onboard the same satellite, which provides the potential for cross calibration and validation for both instruments. Another important difference between the FY3E GNOS II and other GNSS-R science missions is that it operates with global data latency of less than 3 hours. Such a short data latency makes the products of GNOS II available for applications such as data assimilation in operational numerical weather prediction (NWP) models and monitoring of tropical cyclones. The main characteristics of GNOS II are listed below:

- Combination of GNSS RO and GNSS-R;

- GNSS-R with multiple GNSS systems (GPS-R, BDS-R and GAL-R);

- Cooperation with a microwave scatterometer on the same platform;

- Nearly global coverage for Earth observation;

- Operational global data latency of less than 3 hours.

This paper gives an overview of the FY3E GNOS II payload and its GNSS-R product. Section 2 introduces the GNOS II instrument. Section 3 describes the L1 calibration, L2 wind speed retrieval algorithm and data products. Preliminary validation for the wind speed product is presented in Section 4. Summary and future perspective are presented in Section 5 .

\section{Instrument Overview}

The FY3E satellite is in a Sun-synchronous polar-orbiting orbit at an altitude of $836 \mathrm{~km}$ and an inclination of $98.5^{\circ}$. The satellite is a $5.7 \mathrm{~m} \times 3.2 \mathrm{~m} \times 11.6 \mathrm{~m}$ hexahedron, with a total mass of about $2675 \mathrm{~kg}$. The attitude of the satellite is controlled by three-axis stabilization and monitored by an onboard star sensor [13]. Due to its great size and weight, the satellite has an advantage in attitude stability control.

Figure 1 shows an image of the GNOS II instrument. The payload has a total mass of $24.5 \mathrm{~kg}$ and power consumption of $55 \mathrm{~W}$. It has two up-pointed antennas for positioning, 
two side-pointed antennas for GNSS RO and one nadir-pointed antenna for reflectometry. It has eight GNSS-R channels, which can track eight specular points at the same time. It can receive GPS L1, BDS B1 and GAL E1 signals. As it is now in the half-year in-orbit testing stage, the reception of Galileo signals was temporarily turned off. Four channels are now used to process GPS signals and another four channels are used for BDS signals. For BDS, while the transmitting satellites are in three different orbits, including geostationary orbit (GEO), inclined geosynchronous orbit (IGSO) and medium earth orbit (MEO), the receiver was designed to exclude signals from GEO satellites. The major difficulty of using GEO satellites for GNSS-R is that the complete profile of their transmitted effective isotropic radiated power (EIRP) cannot be measured by limited power monitors due to the relative stationary geometry [17].

Figure 2 illustrates the working of GNOS II. The nadir reflection antenna is tilted $20^{\circ}$ backward. This can maximize the signal-to-noise ratio (SNR) of received signals at specular points, as analyzed in [18]. Figure 3 shows the gain footprint on the Earth's surface for the tilted reflection antenna. The peak antenna gain is about $15 \mathrm{~dB}$.

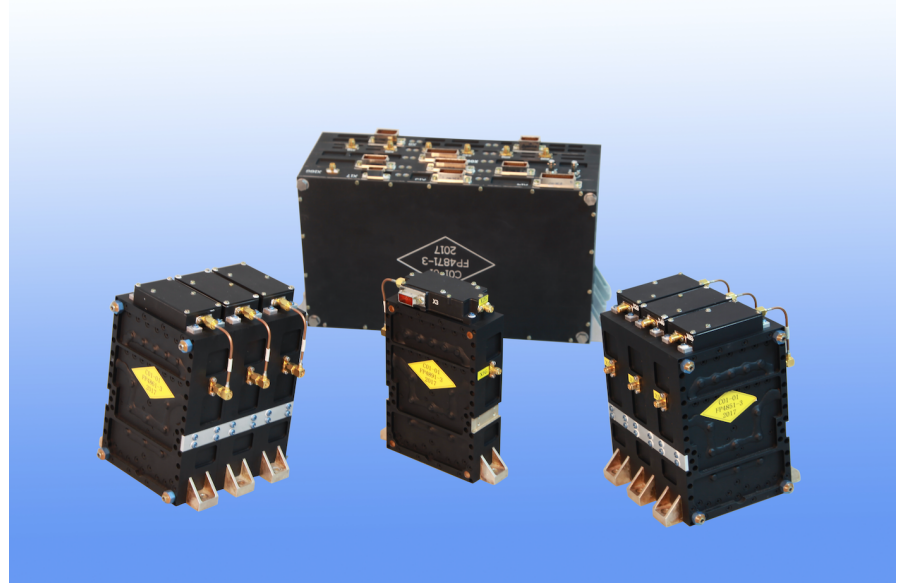

Figure 1. An image of the GNOS II instrument.

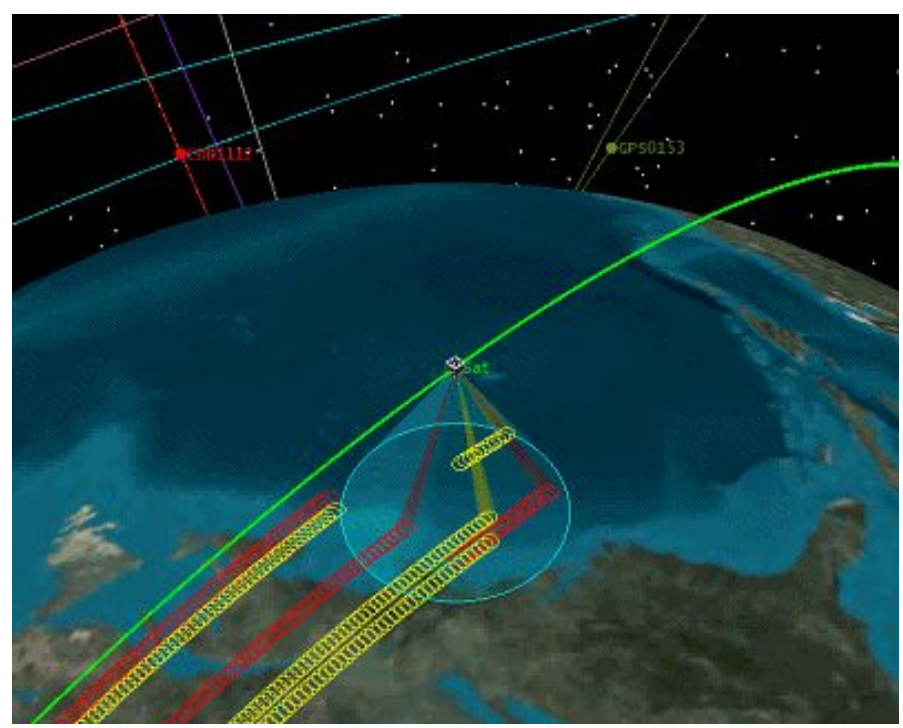

Figure 2. Illustration of the working of GNOS II. The red tracks are specular points from BDS signals and the yellow tracks are specular points from GPS signals. 


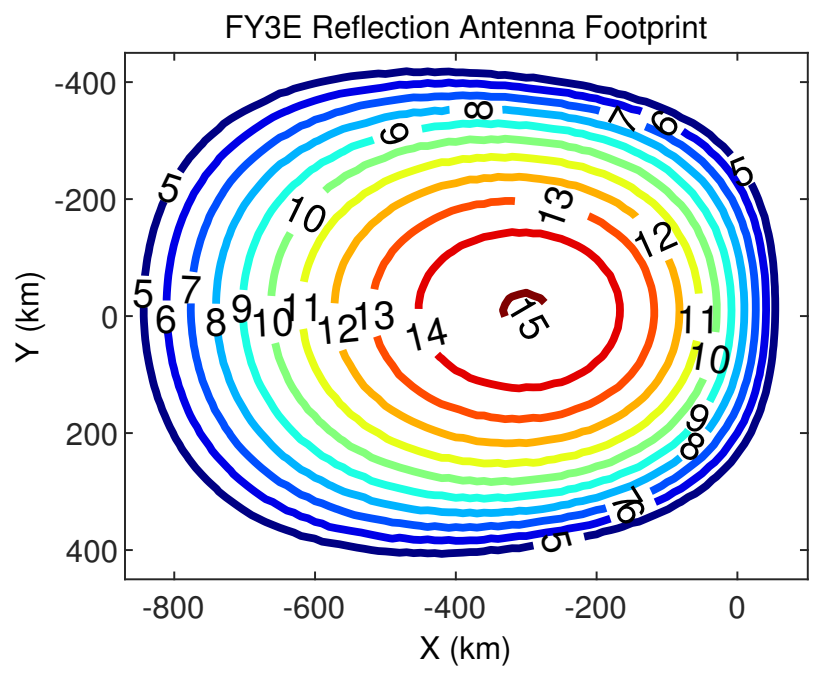

Figure 3. Thereflection antenna footprint on the Earth's surface. The $x$ direction is along-track and the y direction is cross-track. The location with coordinate $(0,0)$ corresponds to the sub-satellite point. The color contour lines stand for the corresponding antenna gain on the Earth's surface in units of $\mathrm{dB}$.

\subsection{Non-Uniform Delay-Doppler Mapping}

The fundamental GNSS-R measurement of GNOS II is the delay-Doppler map (DDM) in raw counts. It is computed by a convolution between the received signal and a GNSS signal replica generated by the receiver coherently for $1 \mathrm{~ms}$ and an incoherent average for $1 \mathrm{~s}$, giving the sampling frequency of DDM of $1 \mathrm{~Hz}$ [19]. The DDM generated by the GNOS II is non-uniform with the dimension of 122 time delays $\times 20$ Doppler frequencies. The resolution of Doppler is $500 \mathrm{~Hz}$ from -5000 to $4500 \mathrm{~Hz}$ with respect to the specular point. The resolution of delay is $1 / 8$ chip from -2.875 to 2.875 chips with respect to the specular point and $1 / 4$ chip elsewhere in the range of -12.25 to 12.125 chips. This non-uniformity characteristic of the DDM is implemented by choosing non-uniform delay intervals $(1 / 4$ chip and $1 / 8$ chip) in the $1 \mathrm{~ms}$ coherent convolution. This high-resolution DDM can provide more sampling near the specular point and increase the accuracy of computed observables. Figure 4 shows an example of the GNOS II DDM.

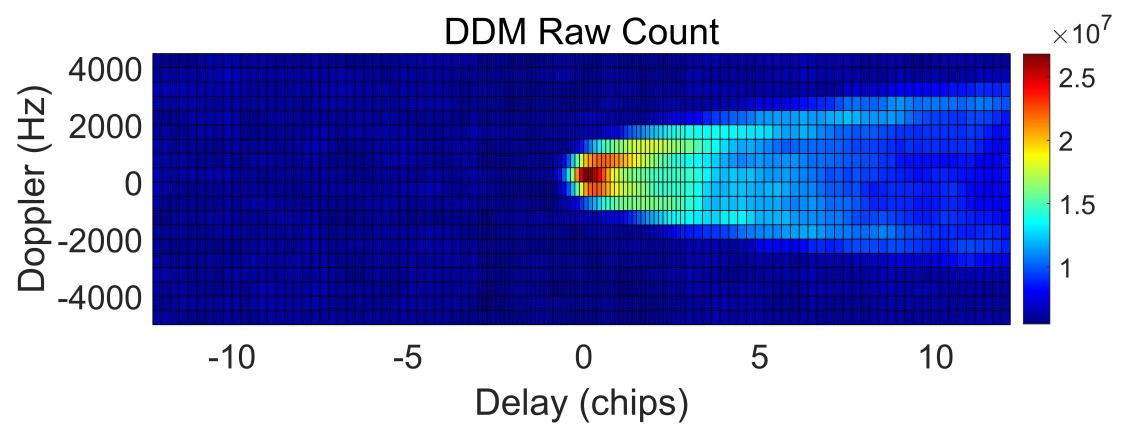

Figure 4. An example of a GNOS II DDM in raw counts.

With the eight reflection channels and $1 \mathrm{~Hz}$ DDM sampling frequency, the receiver can collect $\sim 150,000$ DDMs over the ocean, $\sim 36,000$ DDMs over land and $\sim 30,000$ DDMs over ice each day. Figure 5 shows the number of tracks for each GNSS satellite from GPS and BDS in one day (25 July 2021), where a track is defined as a sequence of consecutive specular points from a same GNSS satellite. Figure 6 shows the number of tracks for each day in August 2021. Note that one track can contain $\sim 520$ DDMs on average and $\sim 1100$ DDMs at most. 

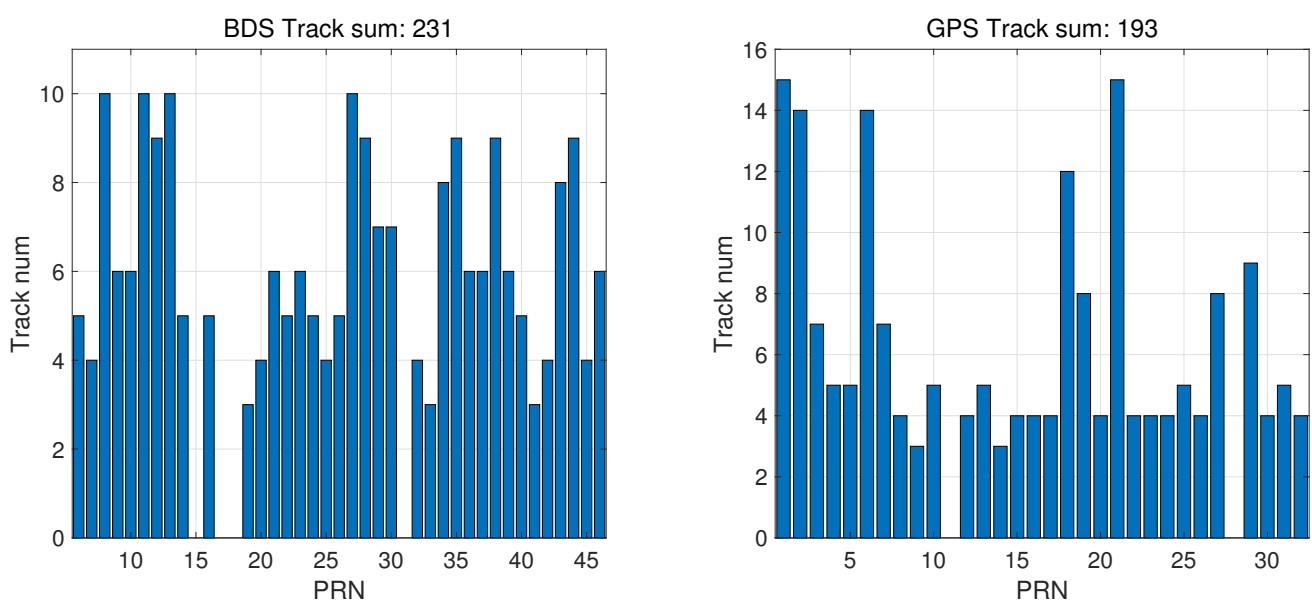

Figure 5. The number of tracks for each GNSS satellite in one day (25 July 2021). The left one is for BDS and right one is for GPS.

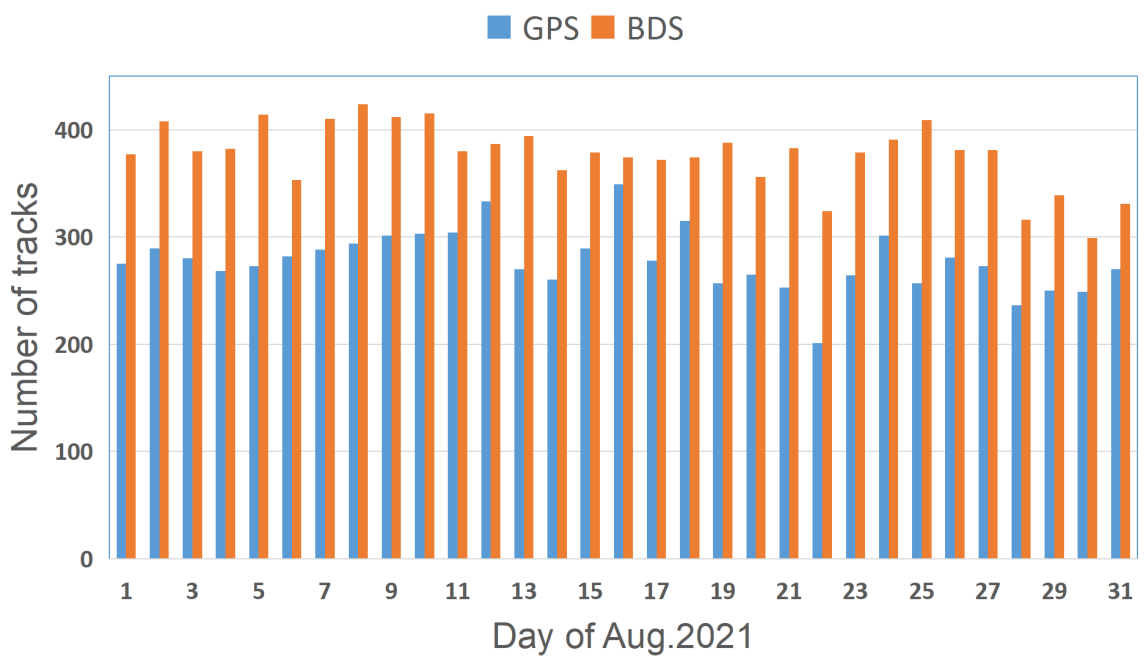

Figure 6. Number of tracks for each day in August 2021.

\subsection{Raw Sampling Data}

GNOS II can also provide raw intermediate frequency (IF) sampling data for scientific applications. The data are in a limited number of collections due to their large volume, but contain more information (carrier phase, multi-GNSS signals, alterable sampling resolution, etc.) than the L1 product described in the next section. Twelve hot points were selected over the globe, among which 10 points are over the ocean (near buoys from the National Data Buoy Center), 1 point is over ice (near the Chinese Arctic Huanghe Station) and 1 point is over land (at the central plain of China). Figure 7 shows the distribution of the hot points. The receiver will switch to raw sampling mode when the distance between the specular point and hot points is less than the operational limit, which is set to $50 \mathrm{~km}$. The length of sampling time is set to $10 \mathrm{~s}$. Note that the locations of hot points, sampling length and operational limit can all be reset onboard. 


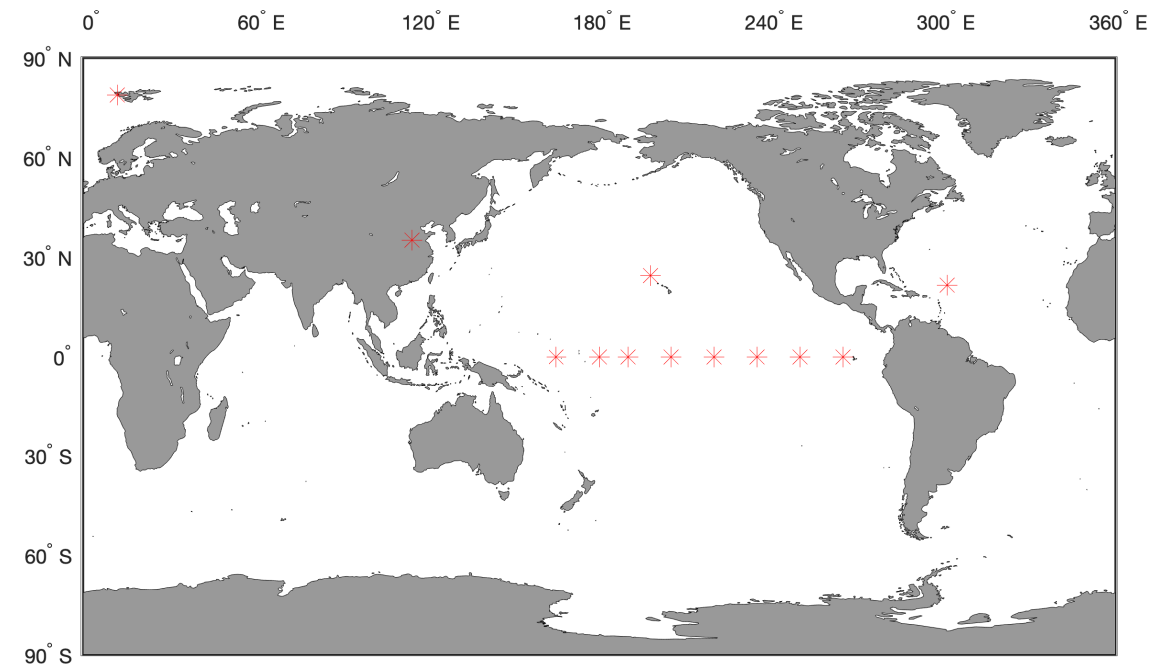

Figure 7. Hot points (red asterisk) for the collection of raw sampling data.

\section{L1 Calibration and Level 2 Wind Speed Retrieval}

The main Level 1 products are the $122 \times 20 \mathrm{DDM}$ as a bistatic radar cross-section (BRCS) and observables for the wind speed retrieval. The main Level 2 products are the retrieved wind speeds and mean square slope (MSS). In the Level 1 calibration, the DDM in raw counts are first converted to DDM power using the total receiver instrument gain G:

$$
Y(\tau, f)=G(T) C(\tau, f)
$$

where $C(\tau, f)$ is the observed $1 \mathrm{~s}$ DDM in raw counts after the incoherent average, $Y(\tau, f)$ is the converted DDM power, $\tau$ is the time delay and $f$ is the Doppler frequency. The instrument gain $G$ is related to the temperature of the instrument, $T$. The relationship between the instrument gain and the instrument temperature was measured by a prelaunch thermal cycling test and saved as a look-up table. The instrument gain of the in-orbit data can then be computed by the pre-launch look-up table and the instrument temperature measured by a temperature sensor in the receiver.

The DDM BRCS is computed from the DDM power using a bistatic radar equation [20]:

$$
\sigma(\tau, f)=\sigma_{0}(\tau, f) A_{e f f}(\tau, f)=Y(\tau, f)\left(\frac{\lambda^{2} P_{t} G_{t} G_{r}}{(4 \pi)^{3} R_{t}^{2} R_{r}^{2}}\right)^{-1}
$$

where $Y(\tau, f)$ is the observed DDM power, $\sigma(\tau, f)$ is the DDM BRCS, $A_{e f f}(\tau, f)$ is the effective scattering area and $\sigma_{0}(\tau, f)$ is the normalized BRCS (NBRCS). $R_{t}$ and $R_{r}$ are geometry terms that can be referenced in [20]. $G_{r}$ is the receiver antenna gain at the specular point. $P_{t} G_{t}$ is the GNSS EIRP. The EIRPs of GPS and BDS satellites are estimated by look-up tables built from data collected by two power monitors at Beijing using a similar method described in [17]. Figure 8 shows the calibrated DDM power and DDM BRCS converted from the DDM raw counts in Figure 4.

The observables for the wind speed retrieval are the delay-Doppler map average (DDMA) and leading edge slope (LES). They are computed from a 5 delay $\times 3$ Doppler box of the DDM NBRCS near the specular point. The algorithms used are similar to the ones in [2]. The wind speed retrieval geophysical model function (GMF) v1.0 was developed by the simulated data generated by an upgraded GNSS-R simulator [21] in the wind speed range of $0-35 \mathrm{~m} / \mathrm{s}$. In the GMF, the retrieved wind speed is a function of the observable and incidence angle at the specular point. The GMFs for GPS and BDS were trained separately. The wind speeds retrieved from the two observables are then combined using the minimum variance estimator [22]. After the wind speed is retrieved by each DDM, a time average is applied to average the wind speed retrieved from a number of consecutive DDMs. The 
number of DDMs for the time average is less or equal to five, limited by the $25 \mathrm{~km}$ spatial resolution. The MSS is computed by the NBRCS $\sigma_{0}$ and Fresnel reflection coefficient $\Re$ as in the equation below.

$$
m s s=\frac{|\Re(\theta)|^{2}}{\sigma_{0}(\theta)} .
$$

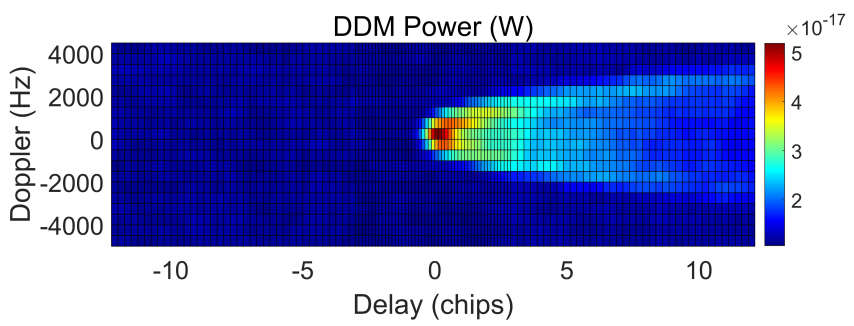

(a)

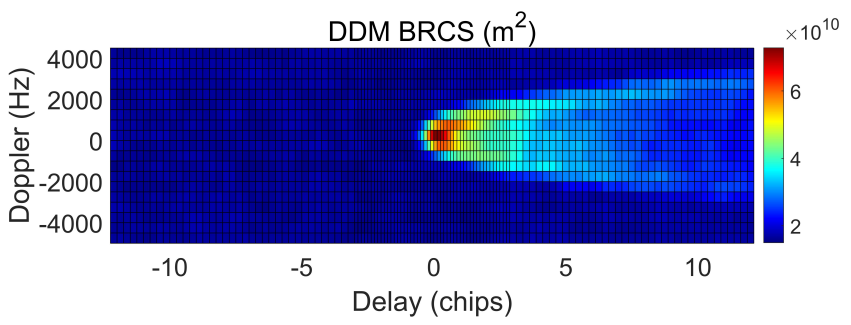

(b)

Figure 8. Calibrated DDM power (a) and DDM BRCS (b) converted from the DDM raw counts in Figure 4.

The Level 2 wind speed product can cover the Earth between the latitude $\pm 85^{\circ}$. Figures 9 and 10 show the Level 2 wind speeds in one day (21 July 2021) and 5 days (21-25 July 2021). The observations of high wind speeds from Typhoon "IN-FA" in the west Pacific Ocean can be observed in Figure 10. Figure 11 shows the Level 2 MSS product over 5 days.

FY3E GNOS II Sea Surface Wind Speed Product (GPS \& BDS)

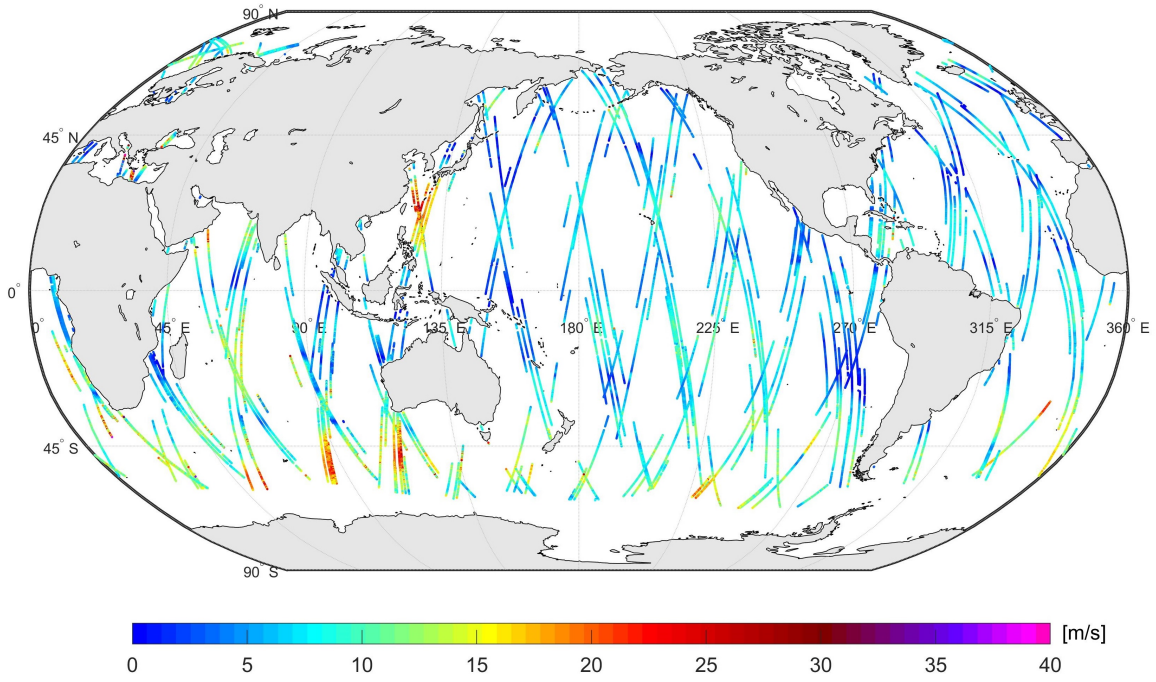

Figure 9. GNOS II Level 2 wind speeds in 1 day (21 July 2021). The color grading represents the Level 2 wind speed. 
FY3E GNOS II Sea Surface Wind Speed Product (GPS \& BDS)

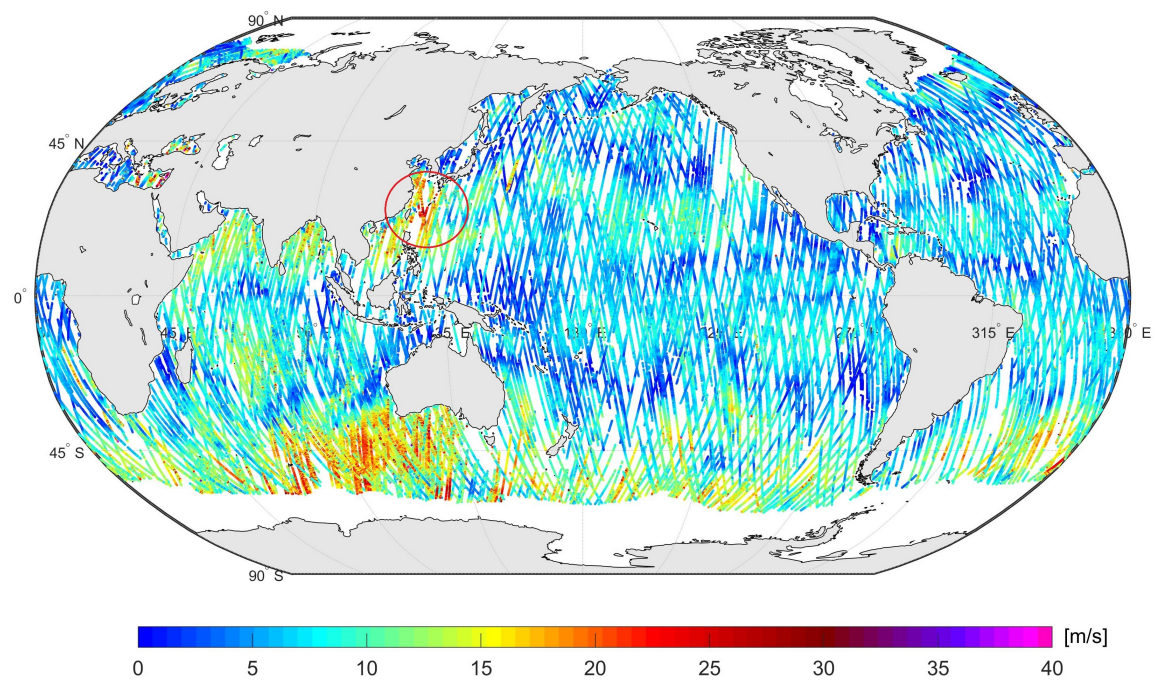

Figure 10. GNOS II Level 2 wind speeds in 5 days (21-25 July 2021). High wind speeds from Typhoon "IN-FA" in the western Pacific Ocean can be observed (red circle).

\section{FY3E GNOS II MSS Product (GPS \& BDS)}

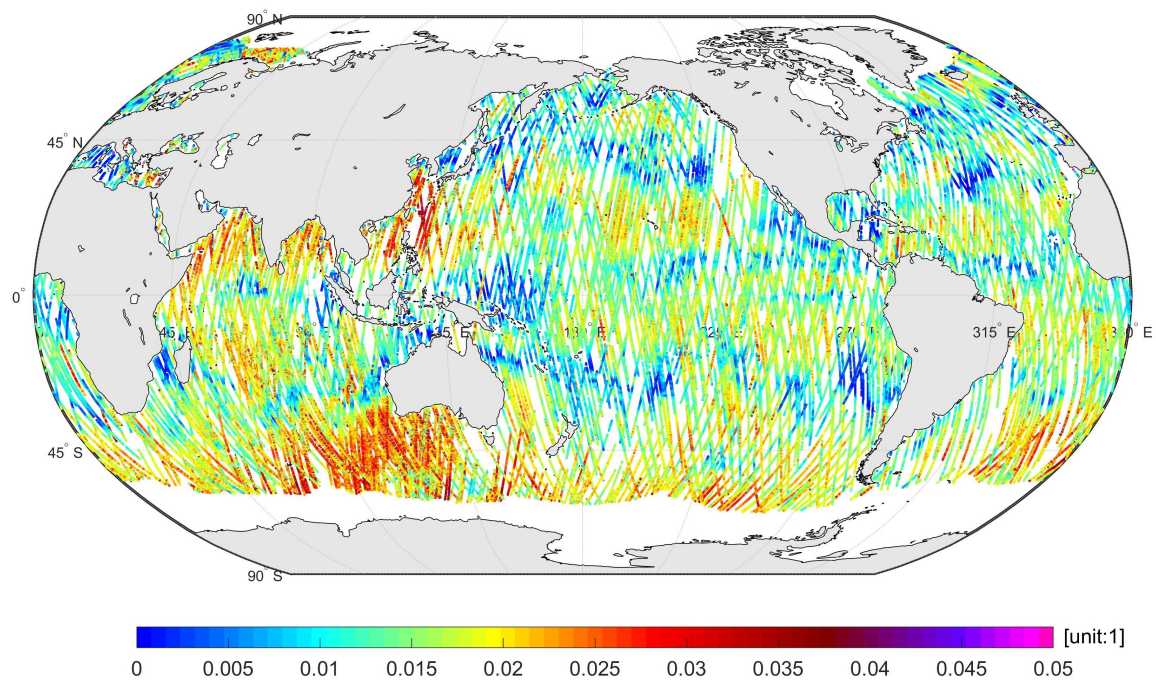

Figure 11. GNOS II Level 2 MSS in 5 days (21-25 July 2021). The color grading represents the Level 2 MSS.

\section{Preliminary Validation Results}

Data from July 10 to October 31 were used for validation in this study. Each specular point was collocated with the wind speed from the ECMWF ERA5 reanalysis [23]. First, the GMFs v1.0 trained by the simulated data was validated by comparing the observables and collocated ECMWF wind speeds. Figure 12 shows the scatter density plots for GPS DDMA and GPS LES observables versus collocated ECMWF wind speeds. Figure 13 shows the corresponding plots for BDS observables. The GMF at an incidence angle of $30^{\circ}$ for each observable is displayed in each figure as well. No obvious dependence on incidence angle was found in GMF v1.0. The results show that the GMFs trained from the simulated data match well with model winds, which validates the power calibration and retrieval algorithm. The development of new GMFs based on real measurements will be future work. 

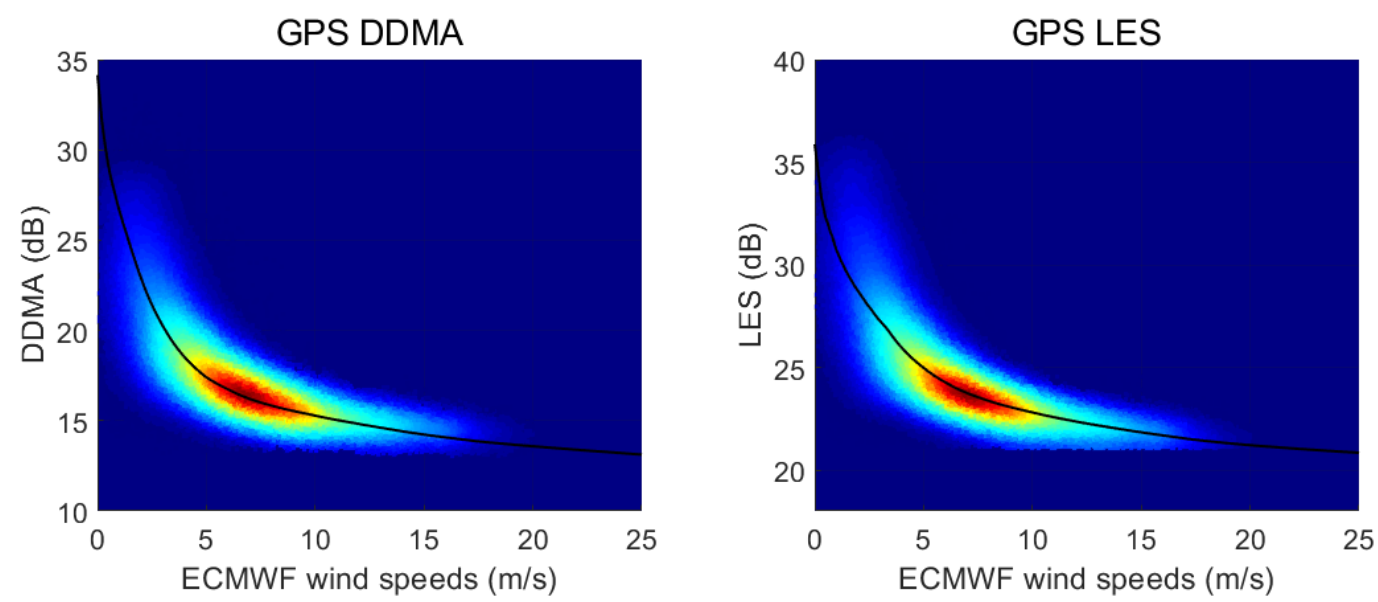

Figure 12. Scatter density plots for GPS DDMA and GPS LES observables versus collocated ECMWF wind speeds. The GMFs are displayed as black lines.
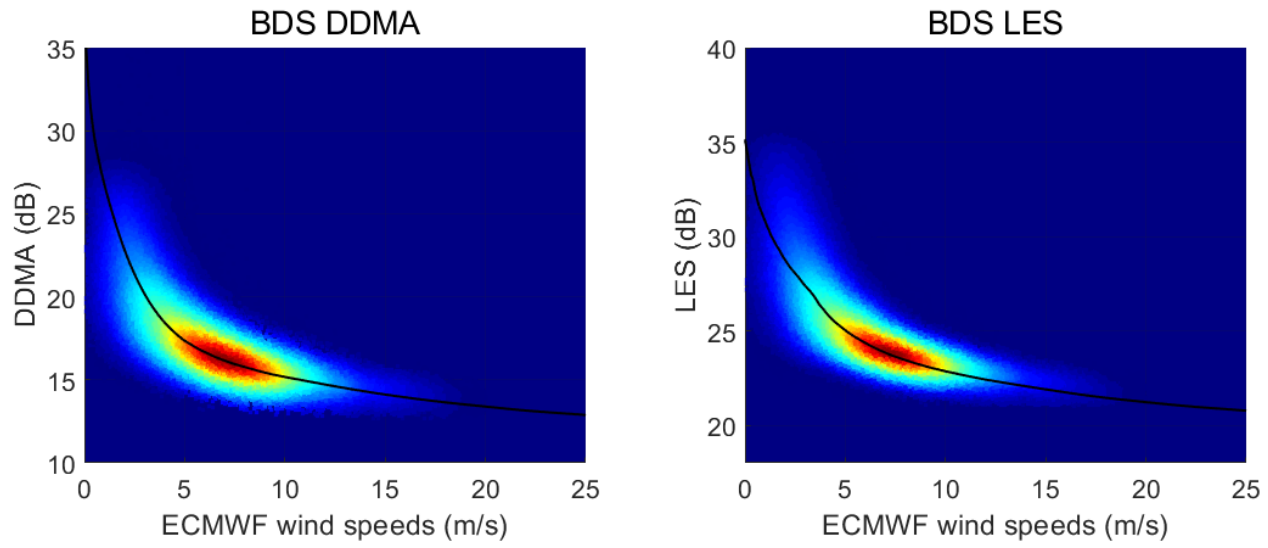

Figure 13. Scatter density plots for BDS DDMA and BDS LES observables versus collocated ECMWF wind speeds. The GMFs are displayed as black lines.

The L2 wind speeds are compared to the collocated ECMWF wind speeds herein. This paper mainly focuses on low to medium wind speeds $(0-20 \mathrm{~m} / \mathrm{s})$, as most samples (>95\%) of wind speed fall into this range and the ECMWF model winds are not accurate enough for high winds (>20 m/s). In the quality control (QC), data with range corrected gain (RCG) less than 15 and DDM SNR less than $-3 \mathrm{~dB}$ were filtered out. The RCG was computed as in [2]. The SNR is computed as

$$
\mathrm{SNR}=\frac{P-N}{N}
$$

where $P$ is the peak value of the DDM, and $N$ is the noise floor of the DDM calculated by averaging the values of the first 20 rows before the specular point in the DDM where only noise exists. The thresholds in the QC were empirically selected to filter out data with low quality which corresponds to about $40 \%$ of the total poputation.

After the quality control, the total numbers of wind speed observations were 3,313,036 for reflections from GPS (GPS-R) and 2,984,509 for reflections from BDS (BDS-R). Figure 14 shows the comparison between the L2 wind speeds and ECMWF wind speeds for data from GPS signals and BDS signals. The results show that most of the data are distributed evenly along the 1:1 diagonal. The root-mean-square error (RMSE) values for GPS-R and BDS-R are 1.78 and $1.70 \mathrm{~m} / \mathrm{s}$. The bias values are -0.06 and $-0.40 \mathrm{~m} / \mathrm{s}$ for GPS-R and BDS-R. The slight negative bias for BDS-R is possibly due to the inaccurate estimation of the GNSS-transmitted EIRP, since all other characteristics (e.g., signal structure and retrieval algorithm) of GPS-R and BDS-R are almost the same. The estimation of GNSS EIRP should be improved in future work. 

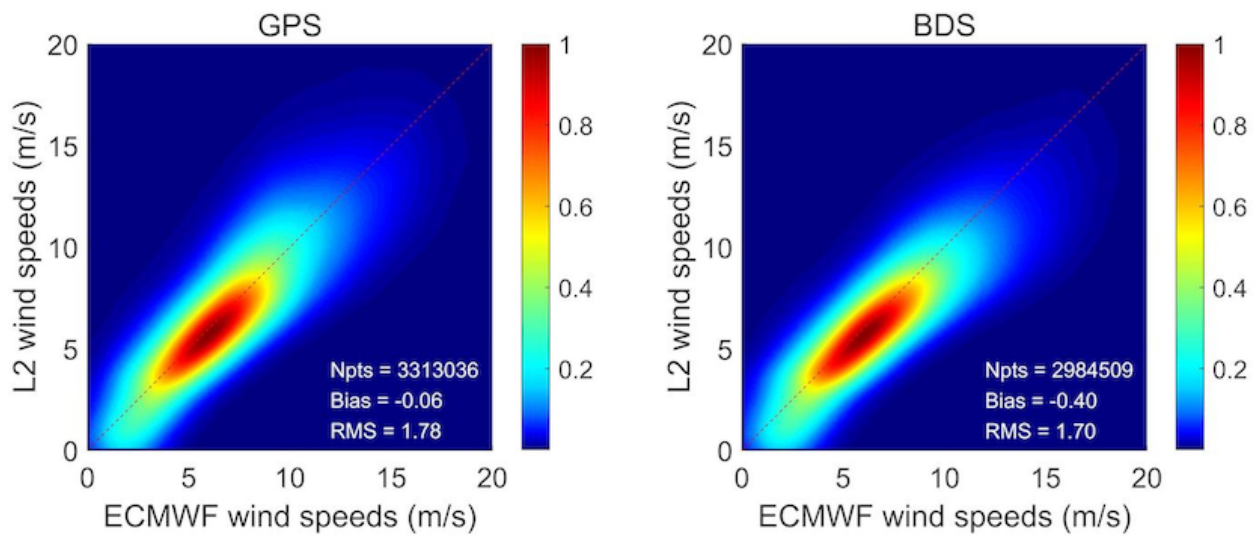

Figure 14. Scatter density plots for the comparison between GNOS II Level 2 wind speeds and collocated ECMWF wind speeds. The left one is for results from GPS signals and the right one is for results from BDS signals.

\section{Summary and Future Perspectives}

The GNOS II on FY3E is the first GNSS-R payload on an operational Chinese meteorological satellite. It successfully integrates GNSS RO and GNSS-R in one instrument, receiving signals from multiple GNSS constellations, such as GPS and BeiDou. This paper introduced the instrument, GNSS-R measurements, data product, power calibration and wind speed retrieval algorithm of GNOS II. Preliminary validation for Level 2 wind speed data in its in-orbit testing stage was presented. For data with RCG larger than 15 and SNR larger than $-3 \mathrm{~dB}$, the overall root-mean-square error of retrieved wind speeds was $1.78 \mathrm{~m} / \mathrm{s}$ for reflections from GPS and $1.70 \mathrm{~m} / \mathrm{s}$ for reflections from BDS at wind speeds below $20 \mathrm{~m} / \mathrm{s}$.

The wind speeds in this paper were retrieved from the GMFs developed from prelaunch simulated data. The next step is to update the GMFs using the real measurements. In addition, the estimation of GNSS transmitter EIRP and the quality control scheme should be refined. Since the wind validation in this paper is preliminary, a comprehensive assessment of the wind speeds retrieved using buoy winds, model winds and other satellite observations (such as scatterometer winds) is expected in the future. In addition, products related to land and the cryosphere, such as soil moisture and sea ice coverage, are currently on the way. In the future, the FY satellite series (including FY3F, FY3R, FY3G, etc.) will all carry GNOS II to establish a GNSS-R observation constellation. The constellation of GNSS observatories will provide larger spatial coverage and higher temporal resolution for Earth observations.

Author Contributions: Conceptualization, G.Y., W.B., J.W., P.Z., X.H. and Y.S.; methodology, G.Y., W.B., Y.S., Q.D., X.W. and Y.C.; software, J.X., F.H., C.Y., X.M., G.T., P.H. and C.L.; data curation, J.X., F.H. and C.Y.; writing-original draft preparation, G.Y., W.B., F.H., J.X. and C.Y.; writing-review and editing, J.W., P.Z., G.Y. and W.B.; project administration, G.Y., J.W., P.Z., Y.S., X.H., N.X., X.Z. and X.X.; funding acquisition, J.W., P.Z. and X.H. All authors have read and agreed to the published version of the manuscript.

Funding: This work is supported by National Natural Science Foundation of China (41774195), the Ten-thousand Talents Program of Jing-Song Wang and in part by the National Natural Science Foundation of China under grant 42074042 and 42104032 and in part by the Youth Cross Team Scientific Research Project of the Chinese Academy of Sciences (JCTD-2021-10) and in part by the Feng Yun 3 (FY-3) Global Navigation Satellite System Occultation Sounder (GNOS and GNOS II) Development and Manufacture Project led by the National Space Science Center, Chinese Academy of Sciences (NSSC/CAS). This work is also supported by Special Fund for Public Welfare Industry (meteorology) (GYHY201306063).

Data Availability Statement: The ECMWF ERA5 reanalysis is available at: https://cds.climate. copernicus.eu (accessed 11 November 2021). 
Acknowledgments: The authors would like to acknowledge Copernicus Climate Change Service for providing the ECMWF ERA5 reanalysis data.

Conflicts of Interest: The authors declare no conflict of interest.

\section{References}

1. Martin-Neira, M. A passive reflectometry and interferometry system (PARIS): Application to ocean altimetry. ESA J. 1993, 17, 331-355.

2. Clarizia, M.P.; Ruf, C.S. Wind speed retrieval algorithm for the Cyclone Global Navigation Satellite System (CYGNSS) mission. IEEE Trans. Geosci. Remote Sens. 2016, 54, 4419-4432. [CrossRef]

3. Li, W.; Cardellach, E.; Fabra, F.; Ribó, S.; Rius, A. Assessment of spaceborne GNSS-R ocean altimetry performance using CYGNSS mission raw data. IEEE Trans. Geosci. Remote Sens. 2019, 58, 238-250. [CrossRef]

4. Wu, X.; Ma, W.; Xia, J.; Bai, W.; Jin, S.; Calabia, A. Spaceborne GNSS-R soil moisture retrieval: Status, development opportunities, and challenges. Remote Sens. 2021, 13, 45. [CrossRef]

5. Wu, X.; Guo, P.; Sun, Y.; Liang, H.; Zhang, X.; Bai, W. Recent Progress on Vegetation Remote Sensing Using Spaceborne GNSS-Reflectometry. Remote Sens. 2021, 13, 4244. [CrossRef]

6. Munoz-Martin, J.F.; Perez, A.; Camps, A.; Ribó, S.; Cardellach, E.; Stroeve, J.; Nandan, V.; Itkin, P.; Tonboe, R.; Hendricks, S.; et al. Snow and Ice Thickness Retrievals Using GNSS-R: Preliminary Results of the MOSAiC Experiment. Remote Sens. 2020, $12,4038$. [CrossRef]

7. Clarizia, M.; Gommenginger, C.; Gleason, S.; Srokosz, M.; Galdi, C.; Di Bisceglie, M. Analysis of GNSS-R delay-Doppler maps from the UK-DMC satellite over the ocean. Geophys. Res. Lett. 2009, 36, L02608. [CrossRef]

8. Foti, G.; Gommenginger, C.; Jales, P.; Unwin, M.; Shaw, A.; Robertson, C.; Rosello, J. Spaceborne GNSS reflectometry for ocean winds: First results from the UK TechDemoSat-1 mission. Geophys. Res. Lett. 2015, 42, 5435-5441. [CrossRef]

9. Ruf, C.; Unwin, M.; Dickinson, J.; Rose, R.; Rose, D.; Vincent, M.; Lyons, A. CYGNSS: Enabling the future of hurricane prediction [remote sensing satellites]. IEEE Geosci. Remote Sens. Mag. 2013, 1, 52-67. [CrossRef]

10. Ruf, C.S.; Chew, C.; Lang, T.; Morris, M.G.; Nave, K.; Ridley, A.; Balasubramaniam, R. A new paradigm in earth environmental monitoring with the cygnss small satellite constellation. Sci. Rep. 2018, 8, 1-13. [CrossRef] [PubMed]

11. Jing, C.; Niu, X.; Duan, C.; Lu, F.; Di, G.; Yang, X. Sea surface wind speed retrieval from the first Chinese GNSS-R mission: Technique and preliminary results. Remote Sens. 2019, 11, 3013. [CrossRef]

12. Munoz-Martin, J.F.; Fernandez, L.; Perez, A.; Ruiz-de Azua, J.A.; Park, H.; Camps, A.; Domínguez, B.C.; Pastena, M. Inorbit validation of the FMPL-2 instrument-The GNSS-R and L-band microwave radiometer payload of the FSSCat mission. Remote Sens. 2021, 13, 121. [CrossRef]

13. Zhang, P.; Hu, X.; Lu, Q.; Zhu, A.; Lin, M.; Sun, L.; Chen, L.; Xu, N. FY-3E: The first operational meteorological satellite mission in an early morning orbit. Adv. Atmos. Sci. 2021, 39, 1-8. [CrossRef]

14. Sun, Y.; Bai, W.; Liu, C.; Liu, Y.; Du, Q.; Wang, X.; Yang, G.; Liao, M.; Yang, Z.; Zhang, X.; et al. The FengYun-3C radio occultation sounder GNOS: A review of the mission and its early results and science applications. Atmos. Meas. Tech. 2018, 11, 5797-5811. [CrossRef]

15. Bai, W.; Wang, G.; Sun, Y.; Shi, J.; Yang, G.; Meng, X.; Wang, D.; Du, Q.; Wang, X.; Xia, J.; et al. Application of the Fengyun 3 C GNSS occultation sounder for assessing the global ionospheric response to a magnetic storm event. Atmos. Meas. Tech. 2019, 12, 1483-1493. [CrossRef]

16. Sun, Y.; Wang, X.; Du, Q.; Bai, W.; Xia, J.; Cai, Y.; Wang, D.; Wu, C.; Meng, X.; Tian, Y.; et al. The Status and Progress of Fengyun-3e GNOS II Mission for GNSS Remote Sensing. In Proceedings of the IGARSS 2019-2019 IEEE International Geoscience and Remote Sensing Symposium, Yokohama, Japan, 28 July-2 August 2019; pp. 5181-5184.

17. Wang, T.; Ruf, C.S.; Block, B.; McKague, D.S.; Gleason, S. Design and performance of a GPS constellation power monitor system for improved CYGNSS L1B calibration. IEEE J. Sel. Top. Appl. Earth Obs. Remote Sens. 2018, 12, 26-36. [CrossRef]

18. Xia, J.; Bai, W.; Wu, X.; Sun, Y.; Du, Q.; Wang, X.; Meng, X.; Liu, C.; Zhao, D.; Wan, Y.; et al. Effect of Lhcp Antenna's Central Beam Direction on DDM's SNR Around Specular. In Proceedings of the IGARSS 2018-2018 IEEE International Geoscience and Remote Sensing Symposium, Valencia, Spain, 22-27 July 2018; pp. 1067-1070.

19. Zavorotny, V.U.; Voronovich, A.G. Scattering of GPS signals from the ocean with wind remote sensing application. IEEE Trans. Geosci. Remote Sens. 2000, 38, 951-964. [CrossRef]

20. Gleason, S.; Ruf, C.S.; Clarizia, M.P.; O’Brien, A.J. Calibration and unwrapping of the normalized scattering cross section for the cyclone global navigation satellite system. IEEE Trans. Geosci. Remote Sens. 2016, 54, 2495-2509. [CrossRef]

21. Bai, W.; Xia, J.; Zhao, D.; Sun, Y.; Meng, X.; Liu, C.; Du, Q.; Wang, X.; Wang, D.; Wu, D.; et al. GREEPS: An GNSS-R end-to-end performance simulator. In Proceedings of the 2016 IEEE International Geoscience and Remote Sensing Symposium (IGARSS), Beijing, China, 10-15 July 2016; pp. 4831-4834.

22. Clarizia, M.P.; Ruf, C.S.; Jales, P.; Gommenginger, C. Spaceborne GNSS-R minimum variance wind speed estimator. IEEE Trans. Geosci. Remote Sens. 2014, 52, 6829-6843. [CrossRef]

23. Hersbach, H.; Bell, B.; Berrisford, P.; Hirahara, S.; Horányi, A.; Muñoz-Sabater, J.; Nicolas, J.; Peubey, C.; Radu, R.; Schepers, D.; et al. The ERA5 global reanalysis. Q. J. R. Meteorol. Soc. 2020, 146, 1999-2049. [CrossRef] 